\title{
François-René de Chateaubriand, Essai sur la littérature anglaise et considérations sur le génie des hommes, des temps et des révolutions
}

\section{Yann Mortelette}

\section{(2) OpenEdition \\ Journals}

Édition électronique

URL : http://journals.openedition.org/studifrancesi/2182

DOI : 10.4000/studifrancesi.2182

ISSN : 2421-5856

Éditeur

Rosenberg \& Sellier

\section{Édition imprimée}

Date de publication : 1 avril 2014

Pagination : 155-156

ISSN : 0039-2944

\section{Référence électronique}

Yann Mortelette, « François-René de Chateaubriand, Essai sur la littérature anglaise et considérations sur le génie des hommes, des temps et des révolutions », Studi Francesi [En ligne], 172 (LVIII | I) | 2014, mis en ligne le 01 avril 2014, consulté le 18 septembre 2020. URL : http://journals.openedition.org/ studifrancesi/2182 ; DOI : https://doi.org/10.4000/studifrancesi.2182

Ce document a été généré automatiquement le 18 septembre 2020.

\section{cc) $(9)$}

Studi Francesi è distribuita con Licenza Creative Commons Attribuzione - Non commerciale - Non opere derivate 4.0 Internazionale. 


\title{
François-René de Chateaubriand, Essai sur la littérature anglaise et considérations sur le génie des hommes, des temps et des révolutions
}

\author{
Yann Mortelette
}

\section{RÉFÉRENCE}

FRANÇOIS-RENÉ DE CHATEAUBRIAND, Essai sur la littérature anglaise et considérations sur le génie des hommes, des temps et des révolutions, texte établi et présenté par Sébastien BAUDOIN, Paris, Société des textes français modernes, 2013, pp. 717.

1 Peu réédité depuis sa publication en 1836, l'Essai sur la littérature anglaise de Chateaubriand n'avait encore jamais fait l'objet d'une édition intégrale préfacée et annotée. En 1984, Marie-Madeleine Martinet en avait commenté les troisième et quatrième parties, qu'elle avait reproduites en fac-similé dans son livre Autorité parlementaire et libertés de l'Angleterre au XVII siècle (Paris, Centre d'histoire des idées dans les îles britanniques). En 1990, Claude Mouchard avait placé les chapitres de l'Essai consacrés à Milton en tête de son édition du Paradis perdu traduit par Chateaubriand. La réédition complète de l'Essai par Sébastien Baudoin comble ainsi une lacune importante.

Dans la préface (pp. 7-82), Sébastien Baudoin rappelle d'abord les liens de Chateaubriand avec l'Angleterre et la genèse du projet de l'Essai, conçu initialement comme une introduction à la traduction du Paradis perdu. Il souligne le caractère novateur de l'ouvrage, les prédécesseurs de Chateaubriand n'ayant présenté que des moments de l'histoire de la littérature anglaise. L'étude de la réception de l'Essai en France et en Angleterre montre que la poétique du fragment et de la digression a désorienté la critique. Chateaubriand avait pourtant anticipé l'objection dans son 
Avertissement: «Dans cet Essai, [...] je m'occupe de tout, du présent, du passé, de l'avenir; je vais çà et là [...]. Ce sont des mélanges qui ont tous les tons, parce qu'ils parlent de toutes les choses. [...] La littérature anglaise n'est ici que le fond de mes stromates ou le canevas de mes broderies» (p. 93). On découvre que Hugo et Vigny n'avaient pas bonne opinion de l'Essai, qui contient quelques attaques contre la nouvelle génération romantique.

3 Sébastien Baudoin s'intéresse ensuite à l'art du compilateur. Il repère les sources utilisées par Chateaubriand, notamment ses emprunts inavoués à la Biographie universelle, ancienne et moderne de Louis-Gabriel Michaud, et signale que l'écrivain recycle ses articles sur la littérature anglaise parus dans le «Mercure de France» de 1800 à 1801, ainsi que des passages de ses futurs Mémoires d'outre-tombe. Il examine les différents genres qui s'entrecroisent dans l'Essai: le discours historique, les considérations philologiques, les observations de critique littéraire, les biographies d'écrivains, les propos polémiques et les éléments autobiographiques. Il note que l'écrivain, à l'instar de Plutarque, aime établir des parallèles entre les génies. Cette solide préface se termine toutefois par une hypothèse hasardeuse sur l'origine du vague des passions chez Chateaubriand: «Ainsi en est-il des vagues, d'où il a peut-être tiré le nom de son mal, le "vague des passions", et qui furent ses compagnes depuis la grève de Saint-Malo» (p. 82).

4 L'Essai sur la littérature anglaise, qui livre notamment le jugement de Chateaubriand sur Shakespeare, Milton, les poètes dits de la nuit et des tombeaux, Walter Scott et lord Byron, méritait une réédition. Celle de Sébastien Baudoin est assortie d'un dossier de près d'un millier de notes (pp. 597-698) et d'un index des principaux noms propres. On regrette qu'elle ne comporte pas de bibliographie répertoriant les éditions françaises et anglaises de l'Essai, ainsi que les ouvrages et les articles le concernant. Une liste récapitulative des abréviations utilisées dans les variantes pour les titres d'œuvres aurait été commode. La préface et l'apparat critique recèlent quelques curiosités orthographiques et syntaxiques: «Chateaubriand rentre [...] de plein pied dans la langue» (p. 61), «va de retro satanas» (p. 63), «l'essence brittanique» (p. 68), «ce qui l'intéresse au plus haut point demeurent les poètes» (p. 68), «au trois-quarts» (p. 74), «pionner» (p. 76), «de temps à autres» (p. 78), «des compte rendus» (p. 600), «CEuvres comlètes» (p. 616), «Béanger» (pour Béranger, p. 699), «Le voyant déjà en "précurseur de Byron", il [Milton] annonce aussi les tourments de 1789» (p. 71), «Le discours autobiographique contamine progressivement la matière de l'Essai. Elle s'y insinue par d'autres procédés» (p. 77). On trouve aussi quelques coquilles dans le texte même de l' Essai, par exemple «parait» (pour paraît, p. 89), «les noms propres imprimées» (p. 91), «le vieille langue anglaise» (p. 485), «l'excédant de notre population» (p. 488), «tontes les Langues» (p. 493). Du point de vue de l'histoire littéraire, on aurait aimé savoir si l' Essai de Chateaubriand a influencé la perception que les écrivains français du XIXe siècle ont eue de la littérature anglaise; à cet égard, une confrontation de l'Essai avec l'Histoire de la littérature anglaise de Taine, publiée chez Hachette en 1863, aurait été intéressante. Ces légères réserves ne remettent pas en cause la grande qualité et la non moins grande utilité de la réédition proposée par Sébastien Baudoin. 